\title{
USO DE OFICINAS DE MAQUETE COMO SUBSÍDIO PEDAGÓGICO PARA O ENSINO DE GEOGRAFIA FÍSICA: EXPERIÊNCIA NA BACIA HIDROGRÁFICA DO RIO ALCÂNTARA, SÃO GONÇALO, RJ
}

\author{
Antônio Enagio Farias de Oliveira ${ }^{(a)}$ Cilene Daudt Vieira ${ }^{\text {(a) }}$ Wendel Guimarães Alves ${ }^{(a)}$ \\ Otávio Miguez Rocha Leão ${ }^{(a)}$ \\ (1) Universidade do Estado do Rio de Janeiro - UERJ/FFP. cilenevieira95@ gmail.com
}

EIXO: GEOGRAFIA FÍSICA: CURRÍCULO, FORMAÇÃO E PRÁTICAS DE ENSINO

\begin{abstract}
Resumo
Com a intensificação do processo de urbanização, os recursos hídricos estão sendo cada vez mais poluídos, principalmente os rios. Esse processo vem ocorrendo no município de São Gonçalo, leste metropolitano do Rio de Janeiro, onde os rios da região encontram-se em sua maioria em estados de degradação, devido sobretudo à ocupação desordenada. Uma das soluções viáveis a serem apresentadas nesse cenário, que pode amenizar essa problemática, é a educação ambiental. O presente trabalho busca apresentar reflexões acerca da importância do ensino da Geografia física nas escolas. O uso de recursos didáticos em sala de aula vem ganhando força na atualidade devido ao grande interesse que o alunado mostra ao ser apresentado a tal experiência. As atividades foram desenvolvidas com turmas do $7^{\circ}$ e $8^{\circ}$ ano do ensino fundamental e $1^{\circ}$ e $2^{\circ}$ ano do ensino médio, as oficinas fazem parte do projeto do PIBID. A maquete foi o recurso didático escolhido para ser aplicados nas oficinas, pois, a mesma proporciona ao discente participação integral com a atividade, pois, se tornam os principais agentes e uma gama de conteúdos é trabalhada ao mesmo tempo, assim também permiti a criatividade dos mesmos, transformando o abstrato em algo concreto para o mesmo.
\end{abstract}

Palavras chave: Ensino de geografia física, bacia hidrográfica, educação ambiental e recurso didático.

\section{Introdução}

A utilização de recursos didáticos variados é de suma importância para o processo de imaterializarão das informações pelo alunado em sala de aula, visto a sua grande relevância em estudar elementos geográficos naturais como vegetação, clima, hidrografia, formas do relevo entre outros, e desenvolver, de forma integrada, a discussão ambiental correlacionada com as características socioeconômicas que compõem as paisagens. Dispor de recursos visuais como fotografias, maquetes, trabalhos de campo, mapas e imagens de satélite é indispensável para o ensino da Geografia.

O aprendizado da Geografia na educação básica é de fundamental importância para o amadurecimento do processo de formação dos alunos que estão se preparando para as etapas seguintes da vida, pois, "a geografia proporciona o conhecimento do espaço geográfico que deve ser entendido, interpretado e analisado" (SOUZA, 2007 p. 23). É, portanto, uma ciência de elevado prestígio em razão de sua importância para compreensão dos mais variados fenômenos 
XVII Simpósio Brasileiro

de Geografia Fisica Aplicada

I Congresso Nacional

de Geografia Física

\section{OS DESAFIOS DA GEOGRAFIA FÍSICA NA FRONTEIRA DO CONHECIMENTO \\ Instituto de Geociências - Unicamp \\ Campinas - SP \\ 28 de Junho à 02 de Julho de 2017}

espaciais (FONSECA, et al. 2011). Seja de natureza humana ou não, o que se desenvolve no espaço geográfico não escapa à análise em Geografia (ROSS, 2009).

Segundo Cuberes apud Vieira e Volquind (2002, p. 11), a geografia é "um tempo e um espaço para aprendizagem; um processo ativo de transformação recíproca entre sujeito e objeto; um caminho com alternativas, com equilibrações que nos aproximam progressivamente do objeto a conhecer". Dessa forma, o ensino de geografia busca formar cidadãos críticos, o que consequentemente cria a necessidade de docentes de aplicarem novas metodologias em sala de aula tornando os alunos seres mais ativos no ambiente escolar. E, neste caso, as oficinas pedagógicas são ótimas opções, pois são formas de construir conhecimento e articular conceitos com a realidade dos discentes. Através da utilização diversificada desses recursos, o professor de geografia assume o papel de orientar na formação de competências e habilidades do alunado, superando a ideias de uma geografia de memorização e enfadonha. Nesse prisma, a maquete é um recurso que orienta a representação do espaço geográfico e permite a percepção do abstrato no concreto.

O presente artigo se refere à elaboração de uma proposta de atividade didática a ser desenvolvida com alunos do Ensino Fundamental e Médio, em aulas de Geografia, cujo tema seja Hidrologia, dentro do conteúdo estruturante "Bacias hidrográfica e a relação com a cidade". Busca-se com a atividade, proporcionar ao aluno a experiência da educação ambiental, bem como a tomada de consciência da importância da preservação de recursos naturais - neste caso a água - em uma perspectiva socioambiental.

Segundo Chorley (1969), a bacia hidrográfica apresenta-se como um importante recorte espacial utilizado na Geomorfologia e Geografia Física. A apresentar uma descrição mais precisa da paisagem. As informações coletadas, particularmente as advindas dos processos fluviais e seus afluentes, até um ponto de saída comum aos canais.

\section{Materiais e Métodos:}

A metodologia de pesquisa qualitativa foi eleita para o desenvolvimento desse trabalho, pois é uma das principais referências para a realização de pesquisas na área da educação. Para a realização da pesquisa, inicialmente, foram realizadas análises e discussões bibliográficas para o entendimento das bacias hidrográficas com foco na hidrologia urbana, e a busca de dados e informações sobre a área de estudo. Além de pesquisas bibliográficas sobre os recursos hídricos, educação ambiental e o ensino da geografia (figura 1). 


\section{OS DESAFIOS DA GEOGRAFIA FÍSICA NA FRONTEIRA DO CONHECIMENTO \\ Instituto de Geociências - Unicamp \\ Campinas - SP \\ 28 de Junho à 02 de Julho de 2017}

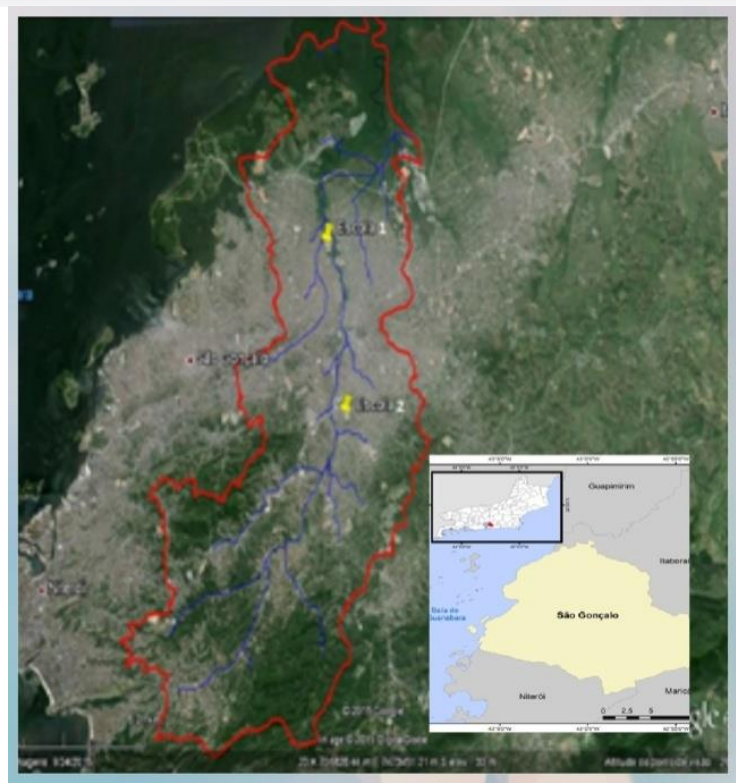

Figura 1: Localização do município de São Gonçalo e bacia hidrografia do Alcântara Fonte: IBGE

A bacia abrange 53 bairros do município de são Gonçalo, os quais se encontram em grande parte urbanizadas. As oficinas são realizadas com o apoio do projeto do PIBID, do departamento de geografia da Universidade do Estado do Rio de janeiro, que iniciou no ano de 2015. As duas escolas encontram-se próximas aos afluentes do rio Alcântara, a primeira escola CIEP-439 Luiz Gonzaga Júnior (escola 1) está localizada entre os Rios Mutondo e Alcântara no bairro Luiz Caçador; a segunda o Colégio Municipal Estephânia de Carvalho (escola 2) localizada no bairro do Laranjal próximo ao Rio Camarões, ambos os rios completamente degradados.

Em um terceiro momento os alunos foram divididos em grupos de cinco pessoas, para o desenvolvimento de uma maquete, com o objetivo de os alunos criasse uma cidade ideal respeitando o espaço dos rios, a parti do conhecimento adquirido com as discussões que antecederam a atividade. A maquete permite uma concreta manipulação e visualização, em terceira dimensão (3D), de diferentes dados e informações á maquete aparece como o processo de restituição do 'concreto' a partir de uma 'abstração', centrando-se aí sua real utilidade, complementada com os diversos usos deste modelo concreto trabalhado pelos alunos" (SIMIELLI et al., 1992, p. 6).

Construção da maquete:

$\mathrm{Na}$ construção da maquete interativa de uma cidade ideal respeitando a natureza, foram estabelecidas algumas regras, o tamanho utilizado uma folha de isopor de $40 \mathrm{~mm}$ e adotados os procedimentos normais para sua construção. O material como base foi o isopor, por ter maior 


\section{OS DESAFIOS DA GEOGRAFIA FÍSICA NA FRONTEIRA DO CONHECIMENTO \\ Instituto de Geociências - Unicamp \\ Campinas - SP \\ 28 de Junho à 02 de Julho de 2017}

mobilidade para manejo dos discentes, cujo pode ser desenvolvidos outros temas: relevo, vegetação, hidrografia, olhar cartográficos e organização do espaço urbano (figura3).

Os matérias utilizados para a construção da maquete: mapa topográfico, escala 1:1.700.000; folhas de isopor, papel camurça diversas cores; garfos de madeira; papel crepom; cartolinas coloridas; Tesoura; vela; clips; cola de isopor; gel azul.

\section{Resultados e discussões}

A educação ambiental é considerada como um processo permanente no qual os indivíduos e a sociedade tomam consciência da condição do seu ambiente e adquirem os conhecimentos, os valores, as habilidades, as experiências e a determinação que os tornem aptos a agir individual e coletivamente e resolver problemas ambientais presentes e futuros. (DIAS 1994, p.148). As oficinas foram desenvolvidas com turmas do $7^{\circ}$ e $8^{\circ}$ ano do ensino fundamental e $1^{\circ}$ e $2^{\circ}$ ano do ensino médio, as oficinas fazem parte do projeto do PIBID do departamento de Geografia da Faculdade Formação de Professores - UERJ.

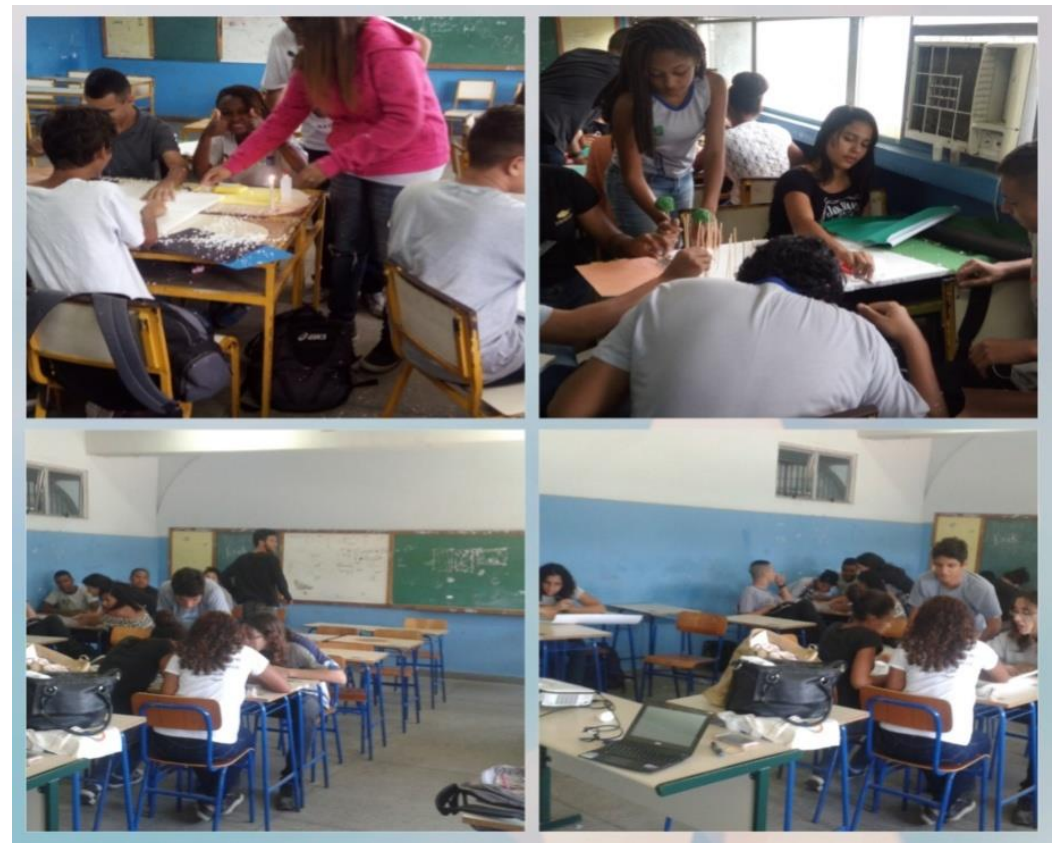

Figura 3: Aplicação das Oficinas

Fonte: Arquivo pessoal

A escolha da maquete como atividade lúdica, foi devido a grande participação que o alunado tem com a atividade, pois, se tornam os principais agentes e uma gama de conteúdos trabalhados ao mesmo tempo, assim também permiti a criatividade dos mesmos. Ao longo da atividade percebemos a maior interação dos alunos, participações com perguntas para tirarem 
dúvidas de como funciona a relação da vegetação com os rios. Foi notória a participação total das turmas com a nova experiência de contar a sua cidade.

\section{Considerações finais}

A perspectiva de apresentação da Geografia Física, através de maquetes interativas e oficinas, permite desenvolver no alunado a capacidade de reflexão, observação, interpretação avaliação e a análise crítica. Habilidades indispensáveis a sua formação e no exercício da cidadania, incluindo os princípios básicos da educação ambiental, passando a ser um agente transformador da nossa sociedade. $\mathrm{O}$ trabalho com maquetes serve como um recurso didático significativo que leve o aluno, ao construir e interpretar as representações cartográficas.

Por fim, é importante salientar a discussão das categorias educação ambiental, escola e bacia hidrográfica que representa uma contribuição de conhecimento da educação ambiental escolar na perspectiva de articulação de atuação entre o espaço de vivência do aluno e o global. A unidade territorial da bacia hidrográfica representa espaços privilegiados de atuação local com impactos globais, sendo a referência do rio como fator de identidade sistêmica.

\section{REFERÊNCIAS}

CHRISTOFOLETTI, A. Geomorfologia. São Paulo: Eggard Blucher, 1980.

DIAS, Genebaldo Freire. Educação Ambiental: princípios e práticas. Editora Gaia, São

Fiscarelli, Rosilene. Material didático: discursos e saberes. Junqueira\&Marin: Araraquara, São Paulo, 2008.

FONSECA, S. F.; SANTOS, S. M.; MARINS NETO, W. 2011. A Geografia Como Instrumento de Análise das áreas de Potencial Turístico em Buritizeiro - MG. I Seminário de Ciência, Tecnologia e Gestão. Faculdade de Ciência e Tecnologia Alto Médio São Francisco FACFUNAM. p. 02-10.

Macedo, L. d.; Petty, A. L. S.; Passos, N. C. Os Jogos e Lúdico na Aprendizagem Escolar. Porto Alegre: Editora Artmed, 2005.

ROSS, Jurandyr Luciano Sanches. Ecogeografia do Brasil: subsídios para planejamento ambiental. São Paulo: Oficina de Textos, 2009. $1^{\text {a }}$ reimpressão.

VIEIRA, Elaine; VOLQUIND, Lea. Oficinas de ensino: O quê? Por quê? Como? 4. ed. Porto Alegre: Edipucrs, 2002. 